\title{
Mental contrasting promotes integrative bargaining
}

\author{
Dan Kirk \\ New York University, New York, NY, USA \\ Gabriele Oettingen \\ New York University, New York, NY, USA, and University of Hamburg, \\ New York, NY, USA, and \\ Peter M. Gollwitzer \\ New York University, New York, NY, USA, and University of Konstanz, \\ New York, NY, USA
}

\begin{abstract}
Purpose - This paper aims to test the impact of several self-regulatory strategies on an integrative bargaining task.

Design/methodology/approach - Participants were randomly assigned to dyads and negotiated over the sale of a car. Before negotiating, participants were prompted to engage in one of three self-regulation strategies, based upon fantasy realization theory (FRT): to mentally contrast a successful future agreement with the reality of bargaining, to exclusively elaborate on successful future agreement, or to exclusively elaborate on the reality of bargaining. Those in the control condition merely began the negotiation.

Findings - Mentally contrasting a successful future agreement with the reality of bargaining leads dyads to reach the largest and most equitable joint agreements, compared to dyads that elaborate only on successful future agreement, or on the reality of bargaining.

Research limitations/implications - Since it was found that mental contrasting promotes integrative agreement, it is important to learn more about the psychological processes that mediate and moderate this effect. Another related line of research would examine the application of the findings to other bargaining scenarios. One further future line of research should combine mental contrasting with planning strategies.

Originality/value - The findings of the paper have implications for both self-regulation and negotiation research. The result that mental contrasting fosters integrative solutions reflects its potential to help negotiators effectively discriminate among feasible and unfeasible components of a multi-faceted goal (integrative agreement). For negotiation research, the paper identifies an effective self-regulatory strategy for producing high-quality agreements.
\end{abstract}

Keywords Negotiating, Agreements, Individual psychology, Targets, Task analysis

Paper type Research paper

\section{Introduction}

The classic example of two sisters splitting an orange is a good illustration of the potential of integrative bargaining, as well as its elusiveness (Follett, 1940). Two sisters both want an orange, and they compromise by cutting the orange in half. What they would have discovered had they discussed it, however, is that one sister wanted the pulp for juice, and the other wanted the peel for a cake. Discovering that they each wanted different aspects of the orange would have helped the sisters to split the orange in a way that each gets the most individual utility out of the agreement. In bargaining there are often opportunities to increase the total utility of an agreement, but still these 
opportunities may be missed. What could the two sisters have done before splitting the orange to discover an integrative solution? Before we can discuss ways to facilitate an integrative agreement, we must first define it.

\section{Integrative agreement}

An integrative agreement, first introduced by Walton and McKersie (1965), is an agreement in which the parties achieve a higher joint outcome than they would with a mere compromise agreement (Carnevale and Pruitt, 1992; Follett, 1940). From our previous example, the compromise solution is to split the orange in half, but the integrative solution is to split the orange by peel and pulp because the two sisters have different, complementary needs. Through integration, each sister obtains a higher individual utility from the agreement.

There are four general ways to reach an integrative agreement: cutting the costs of one party, compensating one party for costs incurred, bridging the two parties' positions (commonly referred to as "expanding the pie"), and logrolling (Pruitt, 1981). When one party wishes to entice a concession from the other, she may attempt to cut the costs of her partner's concession, without substantially hurting her own outcome. A common cost-cutting tactic is to protect the other party's image, to help one's partner "save face," when a concession may lead to diminished status, a sense of rejection, or a sense of reduced freedom (Pruitt, 1981). Encouraging a partner that her concessions are in her best interest, or that she has participated in the decision to concede, versus conceding due to pressure, are examples. One party can also try to compensate the other for costs of a concession, either in the same general category (homologous), or in another area altogether (substitute) (Pruitt, 1981). Swapping a book in exchange for another is an example of homologous compensation. A cash settlement for medical malpractice is an example of substitute compensation.

In cost cutting and compensation, one party does not retreat from the proposed position, but instead makes an agreement more attractive for the other party. The remaining two forms of integrative agreement, bridging and logrolling, require both parties to change their positions in order to agree (Pruitt, 1981). In bridging, a new option is developed that meets each side's primary needs. For example, if a husband and wife plan a vacation, and the husband wants to go to sight-see in New York, but his wife wants to camp near the Delaware Water Gap, a bridging solution would be to go to San Francisco, which has both city options and easy access to camp grounds and hiking trails. In this case, both sides make minor concessions, but a new solution is found that meets each sides main concerns.

The latter option, logrolling, depends on each side's ability and willingness to trade issues with each other (Froman and Cohen, 1970; Walton and McKersie, 1965): parties can achieve higher joint benefits if they make trade-offs on issues that matter differently for each side (Carnevale and Pruitt, 1992). Logrolling differs from bridging because it deals with already articulated demands, where bridging requires the use of some new element, not previously discussed. Nevertheless, in both cases it is necessary to make mutual concessions, to compromise on some issues while pursuing others, and such concessions are "most clearly seen in the case of logrolling" (Pruitt, 1981). The task then is to discover trade-off opportunities, and research has shown that there are a number of cognitive, motivational, and emotional barriers (for reviews, see Thompson et al., 2010, or Lewicki et al., 2007). 


\section{Goals in negotiation}

Because negotiation is a goal-driven activity (Kumar, 1997), researchers have examined the ways in which goals influence bargaining. Negotiators with goals tend to achieve higher profits than those without goals (Neale and Northcraft, 1986; Northcraft et al., 1994), and in bargaining scenarios with uncertainty over the motives and tactics of one's partner, negotiators with general "do your best" goals achieve higher profits than those with specific goals (Polzer and Neale, 1995). While challenging, specific goals have been shown to lead to better performance in a variety of contexts (Locke et al., 1981), negotiators with challenging specific goals fail to incorporate new information and focus on sub-issues instead of the whole negotiation; this is particularly detrimental to negotiations with logrolling potential, because trade-offs require the simultaneous consideration of multiple issues.

It is not enough to set general "do your best" goals, however: a strong commitment to one's goal is necessary to shield from competing impulses that may arise during the negotiation. Negotiators may underestimate the strengths of their impulse to agree, independent of their own profit, because an impasse is often experienced as a personal failure (O'Connor and Arnold, 2001). In situations where a competitive negotiation is expected, people predict that they will behave competitively to achieve their goals, yet still make more concessions and substandard agreements: the desire to agree overpowers the goal to achieve (Diekmann et al., 2003). Therefore, it is important for negotiators to not only set goals but also commit to them, since other motives can interfere as negotiations proceed. In this study, we examine how a self-regulation strategy focused on strong goal commitment can promote integrative agreement.

To negotiate effectively, a strong goal commitment to achieve, coupled with the skill to discover opportunities for integration, can increase the chance of profitable outcomes. Self-regulation research has identified a psychological process, mental contrasting, that produces strong goal commitments and promotes discrimination among feasible vs. unfeasible goals as well as discrimination between effective and ineffective means (i.e. according to high vs. low expectations of success; Oettingen, 2000; Oettingen et al., 2001, 2009; Oettingen et al., in press).

\section{Mental contrasting: the self-regulation of goal commitment}

For strong commitments to feasible goals to emerge, people may use the self-regulatory strategy of mentally contrasting fantasies about a desired future with aspects of the present reality that stand in the way of fantasy realization (Oettingen, 2000; Oettingen et al., 2001). Mentally contrasting future and reality leads people to consider the feasibility of the desired future outcome when committing to a goal. If feasibility (expectation of success) is high, mentally contrasting the desired future with present reality turns the desired future into strong goal commitment, followed by vigorous goal striving. Merely indulging in the desired future, or dwelling on the present reality, does not lead to the consulting of expectations, and in turn evokes only moderate, expectancy-independent, goal commitment.

Mental contrasting and goal commitment. A series of experimental studies supported these hypotheses (for a review see Oettingen and Stephens, 2009). Using various indicators of goal commitment such as cognitive (e.g. making plans), affective (e.g. feelings of anticipated disappointment in case of failure), motivational (e.g. feelings of energization, systolic blood pressure), and behavioral (e.g. invested effort and actual 
achievement), these studies found the postulated pattern of results, whether measuring these indicators via self-report or observations, and whether directly after the experiment or weeks later (Oettingen, 2000; Oettingen et al., 2009; Oettingen et al., 2001; Oettingen et al., 2009; Oettingen, Mayer, Stephens, and Brinkmann, in press; Oettingen, Mayer, and Thorpe, in press). Given high expectations of success, participants in the mental contrasting group showed the strongest goal commitments; given low expectations of success, people showed the weakest goal commitments. Participants in the indulging condition and in the dwelling condition showed moderate commitments, uncorrelated to expectations of success.

Mental contrasting and discrimination in goal pursuit. In a multi-issue negotiation were logrolling can increase profit, it becomes important to recognize which issues are feasible to obtain, and which you may have to concede. Accordingly, mental contrasting enables people to discriminate between likely and less likely future outcomes, and between surmountable and insurmountable obstacles (Oettingen et al., 2000; Oettingen et al., 2001). In two recent studies, Oettingen, Mayer, Stephens, and Brinkmann (in press) observed that mental contrasting helps people discriminate not only between goals, but also between the means to reach those goals. In the first study, students who mentally contrasted not only committed to a goal to seek academic help, but they were able to discriminate between people who might help and might not, and behaved accordingly. In the second study, paediatric nurses who mentally contrasted made strong commitments to improve communication with patients' relatives, and they were able to discriminate among opportunities where the families might respond, versus opportunities where the families might be less responsive. In a negotiation where someone wants to obtain the most profitable outcome possible, mental contrasting should not only help people commit to their goal, but help them discriminate among feasible and less feasible means to their goal.

One can see how the discriminatory processes promoted by mental contrasting might be particularly useful to navigate the give-and-take required to integrate through log-rolling. In logrolling, the means to the desired goal (i.e. profit) are expressed as demands and concessions made to the other party. First, the listing and elaboration of the desired future allows participants to explore potential positive outcomes, identify the most desirable, and form demands. Conversely, the listing and elaboration of reality standing in the way of the desired future allows participants to investigate the most critical obstacles, and decide what may have to be conceded. Mental contrasting, since it promotes discrimination among the means to goal attainment, should help negotiators commit to feasible negotiation demands and concede on unfeasible ones - necessary behaviors for effective logrolling.

Mental contrasting and perspective taking. Since present reality or obstacles in negotiation can be self- or other-focused, mental contrasting not only encourages the exploration of one's own perceived obstacles, but potential obstacles presented by one's partner. Thus it may lead to an enhanced perspective taking, which is a major building block of integrative bargaining (Galinsky et al., 2008).

While mental contrasting's impact on perspective taking has not been studied as extensively as its impact on goal commitment and discrimination, there is evidence of its beneficial impact on the achievement of interpersonal goals, which may require some level of perspective taking. Mental contrasting has been found to promote goal commitment to: seek help from - and provide help to - others (Oettingen et al., in press), 
promote tolerance of and willingness to integrate immigrants (Oettingen et al., 2009), get to know an attractive stranger (Oettingen, 2000), and pursue interpersonal wishes of great importance (Oettingen et al., 2001).

The two sisters chose to pursue the orange because they each wanted to consume it, and felt there was a decent chance of obtaining all or part of it. They decided to cut the orange in half because they both judged that to be a feasible solution. What if the two sisters mentally contrasted over their orange? Through elaboration of the positive future and present reality, might they have developed a better understanding of each other's wishes? One sister might say to herself, "I want some peel, but I really want the pulp" and "what stands in the way of getting the pulp?" - "That my sister wants it too?" The answer to this obstacle is easy: "I will ask my sister whether she actually also wants the pulp!" Consequently, mental contrasting of future and reality when bargaining may foster an understanding of what one wants most and what the other wants most in order to successfully logroll: an ability to discriminate among which demands to make, and which to concede.

Different consequences may emerge if the sisters do not mentally contrast. With only moderate goal commitment to do their best, the sisters might settle for a compromise to reach a fast agreement. One sister might merely fantasize about the desired future (indulge) of obtaining the pulp and drinking the juice, without reflecting on the reality that her sister also wishes to obtain her share of the orange. Her goal commitment is driven by her desire for the pulp and juice, but she does not give much thought to the feasibility of obtaining them. Conversely, she might only reflect on the negative reality (dwelling) of her sister's wish to obtain her share of the orange without exploring her own wishes. In indulging and dwelling, the sisters behave according to their stream of thought, without discovering the integrative solution to logroll peel and pulp. They think one-sidedly, either about obtaining their part of the orange or about the sister relentlessly claiming her part. Consequently, it does not occur to either that it might be feasible to obtain the pulp without the peel. In both cases - indulging and dwelling - goal commitment and discrimination are moderate, so the sisters may walk away with an unfortunate compromise.

\section{The present research}

The self-regulation strategy of mental contrasting should facilitate dyads in an integrative bargaining task to commit to a general achievement goal, as well as make effective trade-offs - to pursue feasible demands, and to concede on those less feasible. Specifically, dyads induced to mentally contrast over successfully solving the task to "earn as many points as possible" should arrive at more integrative and equitable agreements, compared to dyads given the same task instructions, but merely asked to elaborate the future (indulge) or reality (dwell), respectively. Integration, in this case, is the best way for two partners to achieve their personal goals of point maximization. Mental contrasting is operationalized by having participants list and elaborate positive aspects of point maximization, as well as aspects of the present reality standing in the way of such agreements. Indulging and dwelling are operationalized by having participants elaborate on only the positive aspects of point maximization or negative aspects of reality standing in the way, respectively. Each dyad's level of integration and equity are operationalized using a point system, in which participants earn points across eight distinct components of a negotiation for a new car. The point structure is 
designed in such a way that each dyad can earn more points if they recognize the potential for trade-offs, instead of merely negotiating for the most points in each category. Those dyads with the most points reached the most integrative agreements. We also included a measure of equity in our analysis to make sure that high joint gains were truly integrative, and not reached by one side routinely dominating the other: partners with strong commitments to achieve should integrate without conceding too much to the other. We predicted that:

H1. Dyads who mentally contrasted over a general goal to maximize points would achieve the most integrative agreements, measured by joint gain, compared to dyads merely indulging or dwelling.

H2. Dyads who indulged or dwelled would not achieve integrative agreements different from control dyads.

H3. Dyads who mentally contrasted would achieve the most equitable gains, compared to dyads who merely indulged or dwelled.

\section{Method}

Participants

Participants were 174 New York University undergraduate students (102 female), who received class credit for their participation. Participants' ages ranged from 18 to 21 years $(M=19.24$ years, $S D=0.57)$. The study was advertised with the name "Social Decision Making," and potential participants were told that the study would involve making some decisions with other participants in the study.

\section{Procedure}

Participants were invited to the lab in groups of four and were, without their knowing, randomly matched to one another to form a dyad. Each dyad was then randomly assigned to one of four conditions: mental contrasting (MC) $(n=21)$, indulging (I) $(n=22)$, dwelling (D) $(n=22)$, or control (C) $(n=22)$.

Upon arrival, a research assistant escorted participants into individual cubicles, where they remained for the duration of the experiment. Participants never knew who they were partnered with. After reading a brief overview of the study, they were presented with instructions regarding the bargaining task. As an incentive to perform well during the negotiation, they were told that their points earned through bargaining would be converted into lottery entries for a chance to win $\$ 200$, awarded at the end of the study.

As a control variable, before entering into the negotiation, participants filled out two background questionnaires related to their bargaining style. The first was the Social Value Orientation scale (SVO) (van Lange et al., 1997; van Lange, 1999), a 12-item scale designed to categorize participants' bargaining style as "cooperative," "competitive," or "individualistic." Each item contains three hypothetical payouts for the participant and an imaginary partner: one choice awards equal value to the two (cooperative), one choice awards the highest individual gain to the participant (individualistic), and the third offers the greatest disparity between the two outcomes, with the larger amount going to the participant (competitive). Participants who answer 8 of the 12 items consistently are then categorized as "cooperative," "individualistic," or "competitive" in bargaining style. 
To measure subjective negotiation style, after answering the SVO, participants responded to a six-item questionnaire designed to assess their subjective understanding of their bargaining style. Participants responded on a seven-item Likert scale, how "effective," "rational," "emotional," "experienced," "assertive," and "self-interested" they are when bargaining (Kray and Hasselhuhn, 2007). After responding to these items, participants were introduced to the bargaining task.

Integrative bargaining task. The integrative bargaining task, "New Car," was developed by the Dispute Resolution Research Center at the Kellogg School of Business. It is commonly used in business school negotiation courses, and is designed so that partners can earn mutually beneficial agreements if they make trade-offs on issues that matter more to one side than the other. One participant is randomly assigned to the role of Seller of the car and the other is assigned the role of Buyer. They read that the sale of the car depends on negotiating over eight distinct issues: warranty, financing, delivery date, air bags, audio, price, color, and number of extras. Each participant is presented with a chart that assigns points to each issue, and they are told that their task is to negotiate for the most points on each issue that they can. Participants do not see their partner's chart and are instructed not to share any aspect of their chart with their partner. For two issues each side wants the exact opposite outcome ("price" and "delivery date"). For another two issues, each side wants the exact same outcome ("color" and "air bag level"). Four issues, however, are "variable sum" issues: by making mutual trade-offs on two issues of less importance, negotiators can make large gains on issues of greater importance. In this case, "warranty" and "audio" matter significantly more to the Seller's overall outcome, whereas "financing" and "extras" matter significantly more to the Buyer. Therefore, dyads can come to mutually beneficial, integrative agreements if each side secures beneficial outcomes on issues that matter most to them and trade-off on outcomes that matter less. Participants are instructed that they will negotiate with each other anonymously, over an instant messenger program, and that they have 20 minutes to come to an agreement. If they do not, each side is awarded 12,000 points for their efforts. The negotiation is completed as soon as an agreement is reached, or as soon as time expires. Before negotiating, a research assistant entered each cubicle and instructed the participants individually with one of the three strategies of self-regulation (mental contrasting, indulging, dwelling). Participants in the control condition were simply asked to begin the negotiation. Conditions were assigned at the dyad level, so individuals in each pair were given the same strategy induction.

Manipulation of self-regulation strategy. Once participants were familiar with the nature of the negotiation, they received a sheet of paper, entitled "Important Pre-Offer Instruction," that provided them with a general "do your best" achievement goal. The paper read: "Different negotiation tasks emphasize different types of goals. To keep responses constant, we ask that you try your best to achieve as many points as possible." They are also reminded that maximizing their points will maximize their chances to win the end-of-study lottery, and that they will be rewarded 12,000 points if they do not reach an agreement. The reminders serve to reinforce the real consequence of the bargaining task, as well as the participants' BATNA, or best alternative to a negotiated agreement (Fischer and Ury, 1981).

After reading this statement participants were asked to reiterate the number of points they wanted to achieve: "As a rehearsal, please write down the goal in this task 
that is most important to you." Subsequently, the control condition begins the negotiation. The mental contrasting, indulging, and dwelling conditions, on the other hand, are asked to list four aspects of the positive future that they associate with maximizing their points, as well as four main obstacles standing in the way of maximizing their points (i.e. the negative reality of the negotiation). These participants are then asked to elaborate some aspects they had listed, depending upon condition. Specifically, participants in the mental contrasting condition are asked to elaborate on two positive aspects of point maximization (positive future) and two obstacles to point maximization (negative reality), in alternating order, starting with a positive aspect. Participants in the indulging condition are asked to elaborate only on the four positive aspects of the point maximization they had listed. Finally, participants in the dwelling condition are asked to elaborate only on the four obstacles that they listed. The instruction to elaborate read:

Now really think about this [positive aspect/obstacle]. Imagine the relevant events and experiences as vividly as possible! Let your mind go! Do not hesitate to give your thoughts and images free rein. (Take as much time and space as you need to write down what you are thinking. If you need more space to write, please use the back of the page.) Please start writing here:

\section{Dependent variables}

Joint gain. Integrative agreement is operationalized using the point total of the agreement, measured as total points earned by each dyad. This is the sum of the points earned by both Buyer and Seller on each of the eight issues negotiated. If no agreement was reached, each side was awarded 12,000 points, resulting in a 24,000 joint gain for that dyad. Conversely, a dyad that made trade-offs could earn up to 30,000 points, or 15,000 points each. It is possible for one participant in a dyad to earn more than 15,000 points, but at a cost to his or her partner's point total, and to the dyad's combined total.

Equity of gains. A second dependent variable was equity of agreement, operationalized as the point differential between buyer and seller in each dyad. Dyads with equitable agreements had partners who earned roughly the same amount of points, while dyads with inequitable agreements had one partner do significantly better than the other. Equity is another common metric used to evaluate the quality of an agreement, along with the agreement's overall value.

\section{Results}

\section{Equivalence of conditions}

A series of statistical tests were conducted to assess the equivalence of conditions across background variables. A chi-square analysis revealed no significant difference in the distribution of gender across conditions, $X^{2}(3, N=174)=2.09, p=0.55$. As described above, the SVO places a participant in one of three categories if 8 of their 12 choices are "cooperative," individualistic," or "competitive," respectively. By this classification, 47 participants were classified as cooperative, 61 participants as individualistic, and 38 participants as competitive, and 28 participants were unclassifiable, across all four conditions (Mental Contrasting $=6$, Indulge $=5$, Dwell $=10$, Control $=7$,). To simplify analyses, we employed a common method of reducing the groupings from three to two (see van Lange, 1999). Participants with competitive and individualistic responses were classified as "pro-self," while 
participants with cooperative responses were classified as "pro-other." A chi-square analysis also revealed no difference in the distribution of Social Value Orientation across conditions, $\left.X^{2}(3, n=146)=5.73, p=0.17\right)$.

Each condition was also equivalent across each of the 6-items of the bargaining style questionnaire (overall $M=27.22, S D=4.24$ ) $, F(3,166)=0.57, p=0.63$. A principal components analysis did extract a three-item "Competence Scale," consisting of the items that asked participants how "effective," "experienced," and "assertive" they are in negotiating (alpha $=0.79$ ). There were also no significant differences between groups on this scale, $(M=13.43, S D=3.12$,) $F(3,166)=0.60, p=0.62)$.

Since the conditions are equivalent across gender, social value orientation, and subjective negotiation style, we can more confidently interpret any differences between conditions in joint gain and equity of agreement as effects of strategy on negotiation outcome.

\section{Joint gain}

Across 87 dyads, the average agreement totaled $26,016.09$ points $(S D=2273.04)$. This average includes 15 dyads (Groups: $\mathrm{C}=5, \mathrm{D}=6, \mathrm{I}=3, \mathrm{MC}=1$ ) who did not agree in the 20 minutes allotted, who each earned 24,000 total points (12,000 for each side) as the alternative to agreement. To test for the effect of the independent variables, we conducted a series of Univariate ANOVAs. First, we found a main effect of condition on joint gain, $F(3,83)=6.23, p<0.01$. Means and standard deviation by condition are presented in Figure 1. Dyads that mentally contrasted about reaching an agreement achieved significantly higher joint agreements than all other conditions, MC v. I, $t(41)=2.58, p=0.01 ; \mathrm{MC}$ vs. D, $t(41)=4.29, p<0.01 ; \mathrm{MC}$ vs. C, $t(41)=2.17, p=0.03$. While an independent samples $t$-test confirmed our hypothesis that indulging would not lead to a better agreement than merely negotiating, $t(42)=0.42, p=0.68$, groups

Figure 1.

Average points gained per dyad, by condition

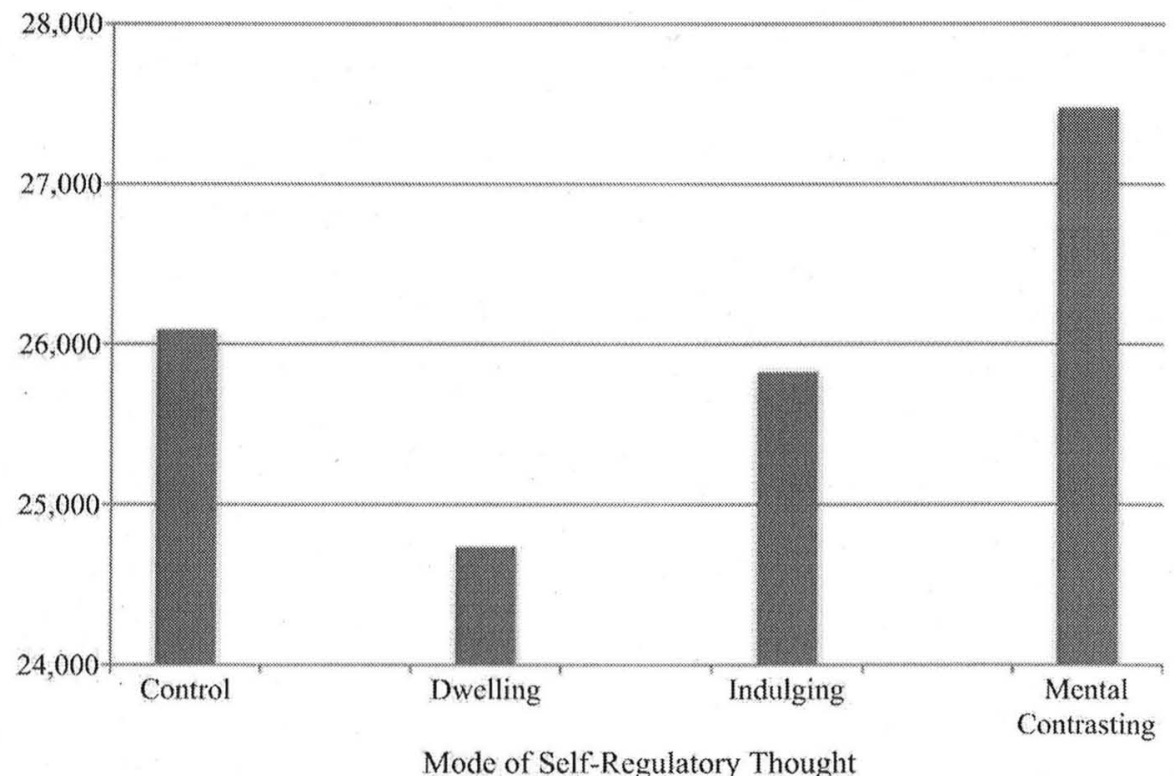

Mode of Self-Regulatory Thought 
that dwelled on obstacles to agreement performed slightly worse than the control, $t(42)=2.10, p=0.04$. There was no significant difference between indulging and dwelling dyads, $t(42)=1.66, p=0.11$ (see Table I).

Additional ANOVAs were run containing the gender, social value orientation, and negotiation pre-measures of each partner as covariates, with joint outcome as the dependent variable. No significant relationships were found for the covariates. The main effect of condition on joint gain remained significant when all of these variables were added as covariates, $F(3,54)=3.60, p=0.02$.

\section{Equity of agreement}

For those groups that did agree, we also analyzed the equity of the agreements, as measured by the point differential between partners' outcomes. The correlation between the equity score and joint gain was not significant, $r=-0.20, p=0.09$. Of the 72 groups that reached an agreement in the time allotted, the mean difference among partners was $M=3,041.67$ points $(S D=2,876.80)$. The mean point differential and standard deviation per condition are presented in Figure 2. While an ANOVA did not reveal a significant difference across condition, $F(3,68)=1.65, p=0.18$, a planned contrast revealed dyads who mentally contrasted came to agreements that were significantly more equitable, $(M=1,910 ; S D=2288.16)$ than the other conditions $(M=3,476.92, \mathrm{SD}=2996.54), t(85)=2.12, p=0.04$ (See Table II).

\begin{tabular}{lccc}
\hline Condition & Mean & Number & Standard deviation \\
\hline Control & 26090.91 & 22 & 2028.11 \\
Dwelling & 24736.36 & 22 & 2244.47 \\
Indulging & 25827.27 & 22 & 2123.16 \\
Mental contrasting & 27476.19 & 21 & 1946.77 \\
\hline
\end{tabular}

Table I.

Average joint gain by condition

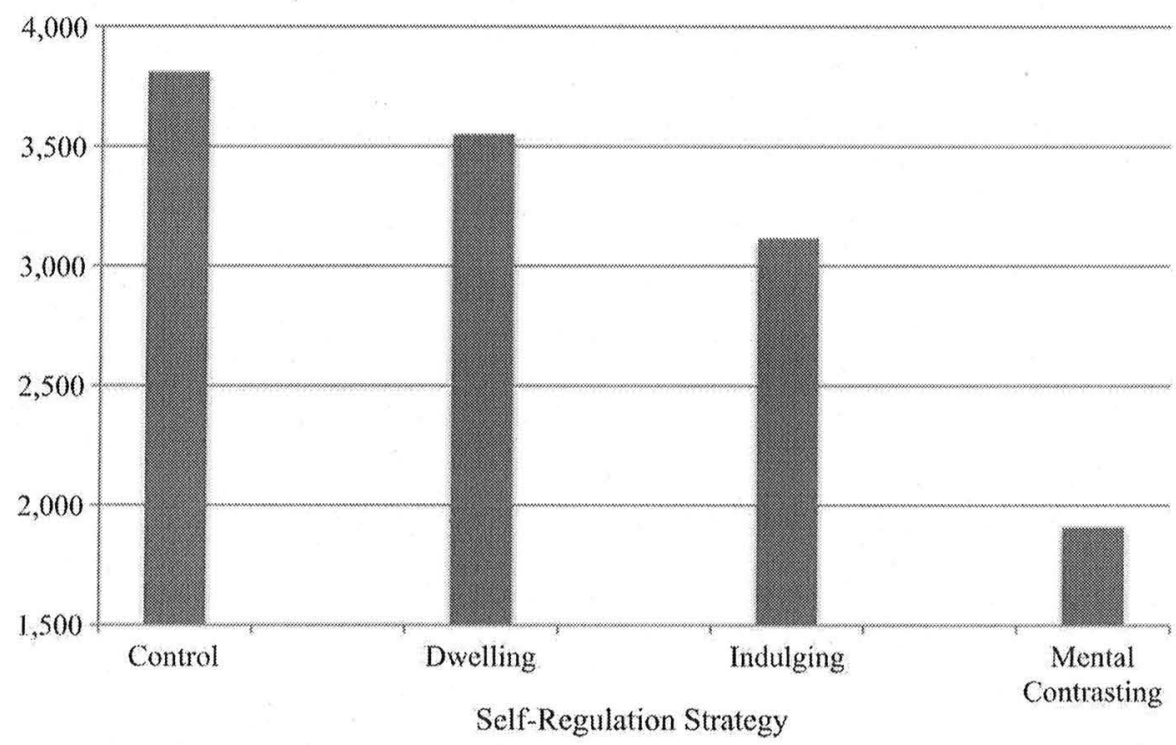

Figure 2. Point differential between partners, by condition 
Similar to our analysis of joint gain, additional ANOVAs containing gender, social value orientation, and negotiation pre-measures of each partner as covariates were conducted and no significant relationships were found for the covariates. The main effect of condition on point differential remained non-significant when all of these variables were added as covariates, $F(3,43)=1.68, p=0.19$. However, a planned contrast comparing the mental contrasting group to the others stayed significant, even when controlling for these covariates ( $\mathrm{M}=-2167.05, S D=996.67), t(85)=2.17$, $p=0.04$. Dyads that mentally contrasted reached agreements that were more equitable than dyads in the other conditions by around 2,100 points.

\section{Discussion}

Mentally contrasting positive aspects of point maximization with the reality standing in the way led to more integrative agreements through logrolling, compared to indulging in positive aspects, dwelling on obstacles, or merely bargaining (Control). The impact of mental contrasting on integrative agreement remained significant even when controlling for social value orientation, subjective negotiation style, gender, and negotiator competence. Contrary to our hypothesis, participants who dwelled on obstacles achieved lower joint gains than control. We will explore this pattern in future research to determine whether dwelling on the obstacles to bargaining does in fact impede integrative agreement. Dwelling on the present reality may have led participants to be preoccupied with their own problems and dispositions. This preoccupation with their own shortcomings may have distracted them from taking the partner's interests into account which should have prevented them from arriving at profitable agreements.

\section{Caveats and outlook}

We found that mental contrasting promotes integrative agreement through logrolling, but there are several caveats that must be made regarding the interpretation of our findings. There are four main caveats we wish to discuss:

(1) the unknown applicability of our findings to other negotiation scenarios, both laboratory and real world;

(2) the lack of evidence for mediating effects of mental contrasting; and

(3) the lack of interaction with individual difference moderators.

We will now discuss each in detail, and offer potential ways in which these questions may be answered.

Mental contrasting in other bargaining scenarios. Our study focused on one pathway to integration - logrolling - but there are other ways to reach an integrative agreement; namely reducing costs of one party, compensating one party for losses, or

Table II.

Point differential by

\begin{tabular}{lccc}
\hline Condition & Mean & Number & Standard deviation \\
\hline Control & 3811.76 & 17 & 3153.94 \\
Dwelling & 3550.00 & 16 & 3461.41 \\
Indulging & 3115.79 & 19 & 2464.25 \\
Mental contrasting & 1910.00 & 20 & 2288.16
\end{tabular}


expanding the pie through bridging (Pruitt, 1981). Furthermore, in this study we gave both partners the same goal and the same self-regulatory strategy, so we don't know what quality of outcomes would have been reached had we mixed goals and/or strategies. In integrative solutions where only one side must mitigate the concessions of the other party - cost-cutting and compensation - it may be sufficient for only one party to mentally contrast, since they are most responsible for the integrative behavior. In logrolling and bridging, however, both sides must make concessions, and therefore it may not be sufficient for only one side to have mentally contrasted. Furthermore, bridging requires the discovery of a novel solution not previously considered, whereas logrolling requires the consideration of issues already on the table.

The question remains whether mental contrasting can promote integration beyond promoting logrolling, and we suggest that behaviors engendered by mental contrasting strong goal commitment, discrimination among the means to goal achievement, and perspective taking - are useful for the other integrative solutions. First, a strong goal commitment to do one's best in a negotiation generally promotes more profitable agreements (Polzer and Neale, 1995); therefore, strong commitments through mental contrasting should lead partners to strive harder in negotiation, and pathways to integration can be discovered. If someone is committed to maximizing their own outcome, it seems reasonable to assume that they will work to find integrative solutions, whether that requires finding a way to help one's partner save face (cost cutting), finding a way to repay a friend for a ride home (compensation), or come up with the idea to vacation in San Francisco, instead of either New York or the Delaware Water Gap (bridging).

Furthermore, all four integrative solutions require the type of discriminatory goal striving engendered by mental contrasting: the recognition of the feasibility of some options, and the unfeasibility of others. When cost cutting by saving face, one must discriminate between a gesture that is palatable versus insulting. Similarly, when coming up with a way to compensate one's partner for a concession, it is essential to recognize what type of compensation that partner requires. In the search for novel solutions required by bridging, the ability to discriminate among feasible and unfeasible new options can lead to the discovery of an integrative agreement.

Discrimination among feasible and unfeasible interpersonal outcomes in bargaining also fosters perspective taking, to understand how to meet one's partner's demands without conceding more than necessary. Perspective taking is a cognitive skill to consider other views of the world (Davis, 1983), and negotiators must often understand their partners' interests to obtain the best outcome for themselves (Thompson, 1990; Fischer et al., 1991). In interpersonal situations, mental contrasting and the elaboration of the present reality standing in the way of point maximization may lead to the consideration of one's partner's interests and goals. A mental understanding of one's partner leads to high-quality agreements, through the reduction of egocentric frames of reference (Moore, 2005), and the anticipation of the behavior of others (Neale and Bazerman, 1983). This is in contrast to an emotional understanding (i.e. empathy) of an opponent, which leads to self-sacrificial concession making (Galinsky et al., 2008). The elaboration of other-focused obstacles in mental contrasting may increase perspective taking, while the strong commitment to achieve may counter any negative effects of empathy.

Mental contrasting as an effective bargaining intervention. If mental contrasting can be applied to different bargaining scenarios, then it has potential to be used in 
real-world negotiations, which are idiosyncratic, requiring one or more integrative solutions, or none at all. One potential problem lies in the ability of someone to learn mental contrasting in one bargaining context, and apply it to another. Recent research demonstrates that mental contrasting can be learned as a meta-cognitive strategy, and subsequently applied to an array of future scenarios across different life domains. In one study, mental contrasting about dieting led not only to eating more low-calorie food, but also to more physical activity; thus, there was a "transfer effect" from one health domain to another (Johannessen et al., 2010). In another study, hospital personnel managers who mentally contrasted over successfully solving their own daily problems reported better time management, less effortful decision-making, and increased project completion, two weeks after receiving initial training. Mental contrasting was learned as a general meta-cognitive strategy and used to deal with a variety of personal and professional problems (Oettingen et al.(in press)). We believe this research underscores the potential to teach mental contrasting as a meta-cognitive negotiation strategy, which can then be applied to different bargaining scenarios.

One new line of research into behavioral interventions combines mental contrasting with planning strategies, and could serve as an additional template for developing bargaining applications. There is evidence that implementation intentions (if-then plans) are an effective goal-striving strategy across several mixed-motive scenarios (Kirk et al., submitted; Troetschel and Gollwitzer, 2007). Future research should explore the effectiveness of combining mental contrasting with implementation intentions (MCII) in various bargaining contexts. Past research has shown that mental contrasting increases a person's readiness to make "if-then" plans (Oettingen et al., 2001), and MCII interventions that capitalize on this effect have proven to be useful self-regulation strategies for effective goal setting and goal striving (Christiansen et al., in press; Stadler et al., 2009; Stadler et al., in press; Adriaanse et al., in press). An MCII intervention in bargaining could help negotiators commit to achievement goals, discriminate among the ways to reach a profitable agreement, and form implementation intentions to make the navigation of the negotiation more effective.

Mediators between mental contrasting and bargaining. In this study we examined the ultimate effect of mental contrasting in bargaining - the total joint outcome as measured by points negotiated - but the mediating behaviors engendered by mental contrasting are an open question. In addition to strong goal commitment and discrimination among feasible and unfeasible outcomes, the other ways in which mental contrasting may impact integrative bargaining is an open question. For example, we suggest the act of perspective taking is intertwined with the discrimination of feasible and unfeasible means to profit maximization, but we have yet to measure this concretely.

What other negotiation behaviors might mental contrasting engender? One possibility is information exchange, by stimulating the articulation of demands. Information exchange is the sharing of one's "goals, priorities, and concerns," and "is a crucial element of joint problem-solving" (Pruitt and Carnevale, 1993, p. 42). Perhaps participants who elaborated on the positive aspects of point maximization were better equipped to elaborate their demands, and the strong goal commitment fostered by mental contrasting led to the articulation of those demands. One can see how this would make information exchange more precise, and thus more effective. 
One potential problem in this scenario is an absence of a measurement of trust, either as a precursor to bargaining, or as an evolving component of the relationship during the bargaining task. Trust, defined as the expectation that an interdependent party will cooperate (Pruitt and Carnevale, 1993), has been shown to be a vital component of effective negotiation, both as an antecedent and consequence (Tomlinson et al., 2009; Lewicki et al., 2007). It is unclear how much our participants trusted their partners and how trustworthy they came across to their partners during the experiment. If trust was high, then people would have had no problem exchanging information. If trust was low however, it could have been built through information sharing, through the fractionation of cooperation into smaller issues, so that the risk in sharing information on any one is relatively small (Carnevale and Pruitt, 1992; Fischer, 1964). Perhaps the strong goal commitment fostered through mental contrasting made it compelling to risk information sharing for the sake of goal achievement, and a feedback loop between information sharing and trust was created; however, we did not measure information sharing in this study.

Individual-level variables and mental contrasting. While we measured several individual-level variables - social value orientation, subjective bargaining style, and gender - we did not measure other individual-level variables important to bargaining. In a recent review of negotiation research (Thompson et al., 2010), three individual-level constructs are identified as the most researched: power, gender, and affect. While we included gender in our analysis and found no interactive effects, the relationship among, power, affect, and self-regulatory strategy are open questions.

In negotiation research, power is often associated with the number and strength of alternatives to agreement (Pinkley et al., 1994). If one party has a highly profitable alternative to agreement, he or she can set higher demands while bargaining, and can resist concession making. Effective use of power thus requires the recognition of one's alternatives, and research has shown that factors other than alternative to agreement can affect demands (Kristensen and Garling, 1997; Pinkley et al., 1994). Mental contrasting, because it fosters discrimination among feasible and unfeasible outcomes, may promote the recognition of alternative outcomes to agreement, and lead to more effective uses of bargaining power.

Affect is a generic term for a range of preferences, moods, and emotions (Kumar, 1997; Fiske and Taylor, 1991). Generally, negotiation research has focused on the effects of positive versus negative affect, and has connected positive affect with a number of effective negotiation behaviors, and integrative agreement, while connecting negative affect to escalation of conflict and sub-optimal agreement (for full reviews, see Kumar, 1997; Thompson et al., 2010). The role of affect in negotiation, however, is still context dependent. Recent research found that in bargaining scenarios with a power imbalance, the more powerful side could use anger expression to claim more value (Sinaceur and Tiedens, 2006). Negative affect has also been shown to promote more careful information processing, as well as signal us to disengage from an unreachable demand, both important bargaining tactics (Kumar, 1997). In the bargaining scenario we used, it is possible that mental contrasting and positive affect would have an additive effect on logrolling. If negative affect were induced in the same scenario, could the positive effects of mental contrasting overcome any urges to act contentious? The interaction between affect and mental contrasting is most likely context dependent, and requires examination. 


\section{Conclusion}

We feel that our findings have important implications for self-regulation and negotiation research. In a bargaining scenario with the potential to integrate through logrolling, dyads that mentally contrasted over a goal to do their best achieved greater and more equitable joint agreements than dyads that merely indulged, dwelled, or negotiated, respectively. In general, self-regulation is integral to effective bargaining, but relatively little attention has been paid to the application of self-regulatory strategies in negotiation (Bazerman et al., 2000). Despite the specific nature of logrolling, we feel that the general self-regulatory benefits of mental contrasting strong goal commitment and discrimination among feasible vs. unfeasible outcomes can be effectively applied to other negotiation scenarios. We also feel that mental contrasting has the potential to engender positive negotiation behaviors such as perspective-taking and information exchange, but more research must be done to determine the mediating effects of mental contrasting, as well as its relationship with potential moderators. In addition, we suggest that the poor performance of dwellers may have been due to the elaboration of only the present negative reality, which activated competitive expectations without strong goal commitment, leading to increased concession-making and sub-optimal agreement.

Whether negotiating over the splitting of an orange or the merger of two companies, a profitable agreement is often an integrative agreement. Integrative agreements, however, are often difficult to construct, and require a strong commitment to one's goal, as well as the ability to discriminate among the means to reach that goal: the demands and concessions to make while bargaining. We hope this study acts as a first step in a new line of research that combines self-regulation and negotiation theory, and leads to the development of effective negotiation interventions. Mental contrasting has proven to be an effective behavioral intervention, which can be learned as a meta-cognitive strategy and applied to different goals: this gives us optimism that mental contrasting can be learned and applied to the idiosyncratic negotiations both inside and outside the lab.

\section{References}

Bazerman, M.H., Curhan, J., Moore, D. and Valley, K. (2000), "Negotiation", Annual Review of Psychology, Vol. 51, pp. 279-314.

Carnevale, P. and Pruitt, D. (1992), "Negotiation and mediation”, Annual Review of Psychology, Vol. 43, pp. 531-82.

Davis, M. (1983), "The effects of dispositional empathy on emotional reactions and helping: a multidimensional approach", Journal of Personality, Vol. 51, pp. 151-84.

Diekmann, K.A., Tenbrunsel, A.E. and Galinsky, A.D. (2003), "From self-prediction to self-defeat: behavioral forecasting, self-fulfilling prophecies, and the effect of competitive expectations", Journal of Personality and Social Psychology, Vol..85, pp. 672-83.

Fischer, R. (1964), "Fractioning conflict", in Fischer, R. (Ed.), International Conflict and Behavioral Science: The Craigville Papers, Basic Books, New York, NY.

Fischer, R. and Ury, W. (1981), Getting to Yes: Negotiating Agreement without Giving in, Houghton Mifflin, Boston, MA.

Fischer, R., Ury, W. and Patton, B. (1991), Getting to Yes, Penguin Books, New York, NY.

Fiske, S.T. and Taylor, S.E. (1991), Social Cognition, Addison-Wesley, Reading, MA. 
Follett, M. (1940), “Constructive conflict", in Metcalf, H. and Urwick, L. (Eds), Dynamic Administration, Harper \& Row, New York, NY, pp. 30-49.

Froman, L.A. and Cohen, M.D. (1970), "Compromise and logroll: comparing the efficiency of two bargaining processes", Behavioral Science, Vol. 30, pp. 180-3.

Galinsky, A.D., Maddux, W.W., Gilin, D. and White, J.B. (2008), "Why it pays to get inside the head of your opponent: the differential effects of perspective taking and empathy in negotiations", Psychological Science, Vol. 19 No. 4, pp. 378-94.

Johannessen, K., Oettingen, G. and Mayer, D. (2010), "Mental contrasting of a dieting wish improves self-reported health behavior", under review.

Kristensen, H. and Garling, T. (1997), "Determinants of buyers' aspiration and reservation price", Journal of Economic Psychology, Vol. 18, pp. 487-503.

Kray, L.J. and Hasselhuhn, M.P. (2007), "Implicit negotiation beliefs and performance: experimental and longitudinal evidence", Journal of Personality and Social Psychology, Vol. 93 No. 1, pp. 49-64.

Kumar, R. (1997), "The role of affect in negotiation: an integrative overview", Journal of Applied Behavioral Science, Vol. 33, pp. 84-100.

Lewicki, R.J., Saunders, D.M. and Barry, B. (2007), Negotiation, 5th ed., Irwin/McGraw-Hilll, Boston, MA.

Locke, E.A., Shaw, K.N., Saari, L.M. and Latham, G.P. (1981), "Goal setting and task performance: 1969-1908”, Psychological Bulletin, Vol. 90, pp. 125-52.

Moore, D.A. (2005), "Myopic biases in strategic social prediction: why deadlines put everyone under more pressure than everyone else", Personality and Social Psychology Bulletin, Vol. 31, pp. 668-79.

Neale, M.A. and Bazerman, M.H. (1983), "The role of perspective-taking ability in negotiating under different forms of arbitration", Industrial and Labor Relations Review, Vol. 36, pp. 378-88.

Neale, M.A. and Northcraft, G.B. (1986), "Experts, amateurs, and refrigerators: comparing expert and amateur decision making in a novel task", Organizational Behavior and Human Decision Processes, Vol. 38, pp. 305-17.

Northcraft, G.B., Neale, M.A. and Earley, P.C. (1994), "Joint effects of assigned goals and training on negotiator performance", Human Performance, Vol. 7, pp. 257-72.

Oettingen, G. (2000), "Expectancy effects on behavior depend on self-regulatory thought", Social Cognition, Vol. 18, pp. 101-29.

Oettingen, G. and Stephens, E.J. (2009), "Fantasies and motivationally intelligent goal setting", in Moskowitz, G.B. and Grant, H. (Eds), The Psychology of Goals, Guilford Press, New York, NY, pp. 153-78.

Oettingen, G., Mayer, D. and Thorpe, J. (in press), "Self-regulation' of commitment to reduce cigarette consumption: mental contrasting of future and reality", Psychology and Health.

Oettingen, G., Pak, H. and Schnetter, K. (2001), "Self-regulation of goal-setting: turning free fantasies about the future into binding goals", Journal of Personality and Social Psychology, Vol. 80, pp. 736-53.

Oettingen, G., Mayer, D., Sevincer, A.T., Stephens, E.J., Pak, H. and Hagenah, M. (2009), "Mental contrasting and expectancy-dependent goal commitment: the mediating role of energization", Personality and Social Psychology Bulletin, Vol. 35, pp. 608-22.

O'Connor, K.M. and Arnold, J.A. (2001), "Distributive spirals: negotiation impasses and the moderating role of disputant self-efficacy", Organizational Behavior and Human Decision Processes, Vol. 84, pp. 148-76. 
Pinkley, R.L., Neale, M.A. and Bennett, R.J. (1994), "The impact of alternatives to settlement in dyadic negotiation”, Organizational Behavior and Human Decision Processes, Vol. 57, pp. 97-116.

Polzer, J.T. and Neale, M.A. (1995), "Contraints or catalysts? Reexamining goal setting within the context of negotiation", Human Performance, Vol. 8, pp. 3-26.

Pruitt, D.G. (1981), Negotiation Behavior, Academic Press, San Diego, CA.

Pruitt, D.G. and Carnevale, P.J. (1993), Negotiation in Social Conflict, Open University Press, Buckingham.

Sinaceur, M. and Tiedens, L.Z. (2006), "Get mad and get more than even: when and why anger expression is effective in negotiations", Journal of Experimental Social Psychology, Vol. 42, pp. 314-22.

Stadler, G., Oettingen, G. and Gollwitzer, P.M. (2009), "Physical activity in women: effects of a self-regulation intervention", American Journal of Preventive Medicine, Vol. 36, pp. 29-34.

Thompson, L. (1990), "Negotiation behavior and outcomes: empirical evidence and theoretical issues", Cognitive Science, Vol. 16, pp. 123-49.

Thompson, L., Wang, J. and Gunia, B.C. (2010), "Negotiation", Annual Review of Psychology, Vol. 61, pp. 491-515.

Tomlinson, E.C., Dineen, B.R. and Lewicki, R.J. (2009), "Trust congruence among integrative negotiators as a predictor of joint-behavioral outcomes", International Journal of Conflict Management, Vol. 20, pp. 173-87.

Troetschel, R. and Gollwitzer, P.M. (2007), "Implementation intentions and the willful pursuit of prosocial goals in negotiations", Journal of Experimental Social Psychology, Vol. 43 No. 4, pp. $579-98$.

van Lange, P.A.M. (1999), "The pursuit of joint outcomes and equality in outcomes: an integrative model of social value orientation", Journal of Personality and Social Psychology, Vol. 77 No. 2, pp. 337-49.

van Lange, P.A.M., Otten, W., De Bruin, E.M.N. and Joireman, J.A. (1997), "Development of prosocial, individualistic, and competitive orientations: theory and preliminary evidence", Journal of Personality and Social Psychology, Vol. 73 No. 4, pp. 733-46.

Walton, R.E. and McKersie, R.B. (1965), A Behavioral Theory of Labor Negotiations, McGraw-Hill, New York, NY.

\section{Further reading}

Adriaanse, M.A., Oettingen, G., Gollwitzer, P.M., Hennes, E.P., de Ridder, D.T.D. and de Witt, J.B.F. (in press), "When planning is not enough: fighting unhealthy snacking habits by Mental Contrasting with Implementation Intentions (MCII)", European Journal of Social Psychology.

Bandura, A. (1986), Social Foundations of Thought and Action: A Social Cognitive Theory, Prentice Hall, Englewood Cliffs, NJ.

Christiansen, S., Oettingen, G., Klinger, R. and Dahme, B. (in press), "A short goal-pursuit intervention to improve physical capacity: a randomized clinical trial in chronic back pain patients", Pain.

Higgins, E.T. and Chaires, W.M. (1980), "Accessibility of interrelational constructs: implications for stimulus encoding and creativity", Journal of Experimental Social Psychology, Vol. 16 No. 4 , pp. 348-61. 
Kappes, A. and Oettingen, G. (2010), "From wishes to goals: mental contrasting connects future and reality", under review.

Kirk, D., Gollwitzer, P.M., Carnevale, P.J. and McMeniman, M. (submitted), "Self-regulation in ultimatum bargaining: accepting profitable offers through goals and plans".

Oettingen, G. and Mayer, D. (2002), "The motivating function of thinking about the future: expectations versus fantasies", Journal of Personality and Social Psychology, Vol. 83, pp. 1198-212.

Oettingen, G., Mayer, D., Stephens, M.E.J. and Brinkmann, B. (in press), "Mental contrasting and the self-regulation of helping relations", Social Cognition.

Stadler, G., Oettingen, G. and Gollwitzer, P.M. (2010), "Intervention effects of information and self-regulation on eating fruits and vegetables over two years", Health Psychology, Vol. 29, pp. 274-83.

Zetik, D.C. and Stuhlmacher, A.F. (2002), "Goal setting and negotiation performance: a meta-analysis", Group Processes and Intergroup Relations, Vol. 5 No. 1, pp. 35-52.

\section{Corresponding author}

Dan Kirk can be contacted at: dan.kirk@nyu.edu 